\title{
DERECHO PENAL MEDIOAMBIENTAL: ¿POR QUÉ O CÓMO?*
}

\author{
Roland Hefendehl
}

\begin{abstract}
A la luz de las recientes propuestas de reforma al derecho penal chileno vinculadas a la protección del medio ambiente, en este trabajo se indican las ventajas y problemas que se han enfrentado en otros sistemas jurídicos al momento de regular la materia y encarar el fenómeno del daño al medio ambiente. El artículo presenta una revisión, entre otros tópicos, del sustrato empírico del derecho penal medioambiental, de su relación y dependencia con la regulación administrativa, de los límites de la criminalización de los daños al medio ambiente y de la posibilidad de establecer sanciones efectivas.
\end{abstract}

Roland HeFendehl es profesor de derecho penal y director del Instituto de Criminología y Derecho Penal Económico de la Universidad Albert-Ludwigs de Friburgo. Es autor de monografías sobre el concepto de patrimonio en derecho penal y sobre los bienes jurídicos colectivos, así como de numerosos artículos en el campo de la criminología, el derecho penal y procesal penal.

* Este artículo está basado en la conferencia pronunciada en octubre de 2007 en el Centro de Estudios Públicos. Agradezco Al Prof. Lucas Sierra por la organización del proyecto y a mi colaborador Moritz Feldmann por sus valiosas investigaciones.

Estudios Públicos agradece a Gonzalo Medina su valiosa colaboración en la revisión y edición de la traducción al castellano. Véanse también en esta edición los artículos "Fundamentos de la Propuesta de la Comisión Foro Penal para la Protección del Medio Ambiente", de Jean Pierre Matus A., y "Comentario Crítico a la Regulación de los Delitos contra el Medio Ambiente en el Anteproyecto de Código Penal de 2005”, de Antonio Bascuñán R. (N. del E.)

Estudios Públicos, 110 (otoño 2008). 


\section{A. Aproximación al tema}

\section{B} asta con abrir cualquier periódico en cualquier momento para confirmar, con triste certeza, que el ser humano está afanado en destruir, de modo irreversible, su medio ambiente. El llamado pacto de las generaciones, o la idea de que un aprovechamiento sustentable del medio ambiente no debe ir en desmedro de las futuras generaciones, suena bien, pero nada tiene que ver con la praxis. Hoy en día uno sólo especula acerca de cuándo quedará sin hielo el Polo Norte. Que esto es ya algo imposible de evitar lo desconocen únicamente los optimistas ingenuos, o intentan ocultarlo industrias carentes de escrúpulos.

Casi resulta curioso que ante este frustrante telón de fondo el derecho penal medioambiental juegue, al menos en los medios de comunicación, un papel importante. En Alemania, la protección del medio ambiente fue trasladada al Código Penal en $1980^{1}$, con el fin también de acentuar su especial importancia para la opinión pública². Hace apenas dos años hubo una decisión espectacular de la Corte Europea de Justicia con relación al derecho del medio ambiente, con la cual se buscaba allanar el camino para un genuino derecho penal europeo en esta materia ${ }^{3}$. Y por último, la protección del medio ambiente desde siempre se ha usado para propagar nuevas formas de sanción, en la búsqueda de una mayor eficiencia preventiva. Como ejemplos de ello se puede mencionar la punibilidad de funcionarios públicos ${ }^{4}$ la responsabilidad penal de las empresas ${ }^{5}$.

Estos pocos aspectos ya muestran la ambivalencia de la materia: llevamos décadas hablando del derecho penal medioambiental y aun así el asunto se nos va escurriendo de manera inexorable. Comprendemos perfectamente el postulado: que no es posible proteger el medio ambiente con una regulación que sólo opera a nivel nacional y que, para lograr una regulación eficiente, probablemente con ello sacrificamos principios jurídico-penales básicos.

Si escribo sobre aspectos criminológicos, dogmáticos y de política criminal de la protección medioambiental penal para una publicación chile-

${ }^{1}$ Mediante la Primera Ley para Combatir la Criminalidad Medioambiental (1. OKG) del 28.3.1980, Bundesgesetzblatt I [Diario Oficial], p. 373.

${ }^{2}$ Bundestags-Drucksache [Publicación del Parlamento Federal]: Considerando oficial, 8/2382, p. 1.

${ }^{3}$ Europäischer Gerichtshof [Corte Europea] (2005), al respecto véase Hefendehl (2006a), pp. 161 ss.

${ }^{4}$ Véase infra E. III.

${ }^{5} \mathrm{Al}$ respecto véase Kloepfer y Vierhaus (2002), Rn. 59 ss. con otras referencias así como más adelante, en F. IV. 2. 
na, es porque ello me parece especialmente provechoso. Pues Chile se beneficia en especial medida de sus recursos medioambientales, sea en sentido económico directo o indirecto, a través del turismo. Y mientras Chile parece estar actualmente dispuesto a trabajar en su derecho penal medioambiental, en Alemania el tema ha perdido atractivo en los últimos años.

A continuación quisiera contribuir a este proceso de reforma refiriéndome especialmente a algunos aspectos de las propuestas que se han formulado en Chile.

\section{B. Conocimientos empíricos}

Es evidente, aunque haya que volver a subrayarlo una y otra vez, precisamente por las rutinas políticas, que toda propuesta de política criminal debe descansar sobre una base empírica sólida. De lo contrario sólo engrosaría las filas del ya extenso ámbito de las políticas legislativas apócrifas, es decir, de las políticas que persiguen objetivos completamente distintos de aquél de la tutela preventiva de bienes jurídicos. Volveré nuevamente a esto, al final de mi exposición, bajo el tópico de la legislación simbólica, es decir, del "governing through crime" 6 .

Cuando hablo de conocimientos empíricos en el campo del derecho penal del medio ambiente aludo tanto a los conocimientos empíricos sobre el derecho penal medioambiental mismo, así como a aquellos sobre el tipo y alcance de la contaminación ambiental.

I. A primera vista, los conocimientos empíricos sobre el derecho penal medioambiental aparecen como los más importantes para nuestro tema, aunque habrá que considerarlos con precaución. Pues, en el caso de la criminalidad medioambiental, se trata de un delito de fiscalización, de modo que el número de casos policialmente registrados depende en forma importante de la relación entre comportamiento de control y comportamiento de denuncia ${ }^{7}$. Y, precisamente, la conducta de denuncia está poco perfilada en los delitos contra el medio ambiente. Existen "mecanismos de neutralización”8 que a menudo llevan al ciudadano a abstenerse de denunciar, ya sea porque se declara incompetente, porque mira hacia al lado o porque no se siente seguro de si se trata o no de una destrucción legal del medio ambiente. En consecuencia, se parte de una elevada cifra negra ${ }^{9}$. La cifra esclareci-

\footnotetext{
${ }^{6}$ Véase infra F. VI. 3.

${ }^{7}$ Véase Eisenberg (2005), § 26 Rn. 7, 49 ss.

${ }^{8}$ Hefendehl (2005), p. 449 ss.; del mismo (2003), p. 31 ss.

${ }^{9}$ Sobre todo ello, véase Bundesministerium des Inneren [Ministerio Federal del Interior] y Bundesministerium der Juztiz [Ministerio Federal de Justicia] (2006), pp. 264 ss, así como Bundeskriminalamt [Oficina Federal de Investigación Criminal] (2006), pp. 30, 214 ss.
} 
da, aun con un concepto muy amplio de criminalidad medioambiental (incluidas las infracciones a normas penales accesorias) alcanza sólo a aproximadamente el 0,5\% de la criminalidad total (sin contar los delitos contra el Estado ni los delitos del tráfico rodado). El número total de delitos contra el medio ambiente registrados policialmente en Alemania aumentó claramente desde el comienzo de su levantamiento estadístico hasta alcanzar su nivel máximo en 1998. Aunque desde 1999 en adelante bajan las cifras, tanto en forma absoluta como relativa. Entretanto ha alcanzado el nivel de mediados de los años ochenta. En los años ochenta predominaba la contaminación de las aguas según el § 324 del StGB, pero a partir de 1991 comienza a predominar la evacuación de residuos peligrosos para el medio ambiente según el $\S 326$ del StGB. Otros datos empíricos orientadores son una probabilidad extremadamente baja de acusación formal, así como un bajo nivel de sanción, lo que en cada caso se explica por una gravedad estimada como baja de los delitos contra el medio ambiente.

II. Valga lo dicho hasta aquí. Ya que, independientemente de estos antecedentes, la verdadera y dramática calamidad reside en la esfera de lo legal. Así, la Comisión Europea ha constatado que el tráfico rodado y los procesos de combustión en los hogares particulares y en la agricultura superan en ciertos sectores incluso a la emisión de contaminantes de las grandes plantas industriales ${ }^{10}$. De modo que son dos los temores que se evidencian: primero, que la cifra negra en el terreno del crimen medioambiental es vasta y, segundo, que la esfera de lo legal no punible ocupa un vasto espacio, ya sea porque empresas económicas han hecho legalizar su conducta, ya sea porque se trata de una actividad que esencialmente no requiere de permisos, como la calefacción del hogar.

\section{Globalización e internacionalización}

I. La impotencia de cada Estado frente a la globalización se hace patente de un modo especialmente dramático en el campo del deterioro del medio ambiente. De requerirse un derecho penal global, entonces sería en este ámbito ${ }^{11}$. Baste a modo de ejemplo analizar el emplazamiento de las centrales de energía nuclear francesas sobre la frontera con Alemania, sometidas a permanente viento oeste, para comprobar que las fronteras nacionales no tienen relevancia en muchos casos de delincuencia medioambiental $^{12}$. Hasta ahora todas las convenciones internacionales expresan úni-

${ }^{10}$ Europäische Kommission [Comisión Europea] (2006).

${ }^{11} \mathrm{Al}$ respecto, Schünemann (2003), pp. 299 ss.

12 Respecto de semejantes daños medioambientales transfronterizos, véase Hecker (2003), pp. 880 ss. 
camente que los mayores destructores de recursos a nivel global se refrenan en gran parte por intereses económicos. Esa política calza a la perfección con la dinámica de desarrollo que generó la globalización. Pues la globalización consiste en lo medular — así Schünemann — en la liberación a la economía de los tradicionales límites culturales, y con ello también legales, del Estado nacional. La vanguardia de ese desarrollo la constituye Estados Unidos, que sigue considerando al movimiento ecologista como el verdadero factor de freno de la “economización”, y, por ello, busca consecuentemente impedir una globalización del derecho medioambiental y del derecho penal medioambiental.

II. Con esa crítica de fondo, podrían considerarse como un avance los esfuerzos europeos por sentar estándares mínimos para una protección penal del medio ambiente. Sin embargo, las reformas propuestas en la esfera material $^{13}$ no logran atacar los problemas más decisivos y terminan siendo more of the same (más de lo mismo). Junto a ello se apuesta por la responsabilidad de las empresas, lo que también se encuentra en lugar destacado en la agenda del proceso de reforma chileno. Volveré sobre esto, como también sobre las nuevas sanciones propuestas ${ }^{14}$, al concluir la presentación.

\section{Líneas fundamentales del derecho penal medioambiental chileno}

El derecho penal medioambiental chileno se encuentra en vías de ser reformado. En un primer paso bosquejaremos la situación actual y los proyectos de reforma. En un segundo paso procederemos a comparar esos proyectos de reforma con otros modelos y veremos su desarrollo ulterior.

I. El Art. 19, No 8 de la Constitución chilena establece, a semejanza del Art. 20a de la Ley Fundamental alemana, que la protección del medio ambiente es un fin del Estado. Mientras que en la Constitución alemana se destaca también la responsabilidad respecto de las generaciones futuras, el encabezamiento de la Constitución chilena habla del derecho de vivir en un medio ambiente libre de contaminación. En estas formulaciones puede identificarse la importancia del medio ambiente, aunque en ellas el valor autónomo pasa a segundo término respecto del valor al servicio del ser humano.

II. La regulación penal vigente se caracteriza por una ordenación no sistemática y dispersa, que por lo demás se encuentra en el área de intersección de bienes jurídicos individuales clásicos, como la salud y el patrimonio,

${ }^{13}$ Cf. especialmente la propuesta de la Europäischen Kommission [Comisión Europea] (2007) sobre la protección penal del medioambiente del 9. 2. 2007.

${ }^{14}$ Véase infra F. IV, así como F. V. 
la protección del medio ambiente y algo como la protección de la diversidad de las especies o de las plantas. De acuerdo con la interpretación tradicional, esta última no puede en absoluto subsumirse correctamente bajo el concepto de bien jurídico ${ }^{15}$. Ese conglomerado no permite realzar lo específico del derecho penal medioambiental. Naturalmente que a través del medio ecológico pueden resultar menoscabados la salud y el patrimonio, pero para ello no se requiere de un tipo penal autónomo. Semejantes afectaciones del bien jurídico ya se hallan cubiertas por los correspondientes tipos legales para la protección de la integridad física y del patrimonio ${ }^{16}$.

III. El proyecto de ley sobre los delitos contra el medio ambiente de 1998 contiene un tipo básico que se ocupa de los peligros para la integridad física o la vida y un tipo privilegiado que trata "únicamente" del riesgo para el medio ambiente. Aquí también se plantea la interrogante de si se hace justicia a la importancia del derecho penal del medio ambiente cuando se lo considera solamente en relación con el potencial de la interrogante de cuáles afectaciones actuales de bienes jurídicos individuales se vinculan con él.

IV. El Foro Penal 2005 valora acertadamente el papel del derecho penal en su función de última ratio, enfoca la cuestión central de la llamada accesoriedad administrativa, aboga por la protección del sistema administrativo que regula el medio ambiente y desarrolla el concepto del "daño medioambiental grave”. Distingue entre dos variantes de imprudencia: por una parte, se podría actuar de modo imprudente durante la actividad, por otra, se podría actuar de modo imprudente al exceder el permiso. El Foro Penal es flanqueado por un proyecto de ley relativo a los delitos contra el medio ambiente cometidos por personas jurídicas. En el mismo se subraya que el derecho penal debe proteger las condiciones y los fundamentos necesarios para la vida del ser humano y de la comunidad, y que de ese modo debiera convertir a la protección del medio ambiente en uno de los temas principales del derecho penal. También esta vez se pone de relieve la protección de los bienes jurídicos individuales.

\section{E. Líneas fundamentales del derecho penal alemán en perspectiva crítica}

En un próximo paso quisiera ahora exponer las líneas fundamentales del derecho penal del medio ambiente alemán y criticarlas parcialmente.

\footnotetext{
${ }^{15}$ Hefendehl (2004), pp. 238 ss.; del mismo (2001), p. 499.

${ }^{16} \mathrm{Al}$ respecto, sobre ello en conjunto, Steindorf (1997a), Rn. 12 ss.
} 


\section{Bien jurídico y estructura del delito}

Por bien jurídico protegido se entiende el medio ambiente - $-\mathrm{y}$ éste en sus diversos medios (agua, suelo, aire)—, además de sus otras formas de manifestación (mundo animal y vegetal) ${ }^{17}$. Por regla general se pone énfasis en que no debe perderse la vinculación con el ser humano. Una concepción ecocéntrica del bien jurídico no se podría compatibilizar con la tarea del derecho penal, que debe hacerse cargo de la conducta dañosa para la sociedad y, con ello, para los miembros de ella ${ }^{18}$. Ahora bien, en Alemania se ha hecho gran despliegue dogmático para demostrar una relación entre un bien jurídico y, por ejemplo, una contaminación de aguas ${ }^{19}$. Cabe distinguir entre dos casos: en un accidente químico, por ejemplo, a raíz del cual las aguas son contaminadas de un modo que causa exantemas patológicos, se trata de un delito de lesión o de un delito de peligro concreto, naturalmente en consideración al bien jurídico individual de la salud. En la otra constelación, en que si bien las aguas son contaminadas pero no se suscita en forma directa una consecuencia patológica para el ser humano, no tiene la afectación de un determinado medio ambiente influencia directa alguna en los bienes jurídicos individuales. En este caso, ateniéndose a la tríada estructural del delito — delito de lesión, delito de peligro concreto, delito de peligro abstracto-, se considera solamente un delito de peligro abstracto. A mí me parece que es justamente en la esfera de los delitos contra el medio ambiente donde resulta apropiada la precisión acerca de un así llamado delito de acumulación ${ }^{20}$. Pero el llamado “delito de aptitud” previsto por el legislador alemán entre los delitos contra el medio ambiente parece fuera de lugar. Semejante delito se presenta cuando el legislador, por ejemplo, busca enfocar el vasto campo de las conductas a través de una cláusula de aptitud, como en el caso de la difamación. Un análisis de estos llamados delitos de aptitud revela, sin embargo, que sólo tienen lugar en el caso de los bienes jurídicos individuales. Pues si el tipo legal protegiese un bien jurídico colectivo, entonces la cláusula de aptitud tampoco sería capaz de generar una relevancia directa para el bien jurídico ${ }^{21}$. La técnica legislativa alemana rechaza el dogma recién descrito de la reconducción del bien jurídico a la persona humana, cuando, por ejemplo, en el $\S 324$ a del StGB se penalizan acciones que son aptas para dañar animales y plantas de valor

${ }^{17}$ Schmitz (2006), Rn. 11.

${ }^{18}$ Steindorf (1997a), Rn. 13.

${ }^{19}$ Véase Kloepfer y Vierhaus (2002), pp. 73 ss.

${ }^{20}$ Detalladamente en Hefendehl (2002), pp. 183 ss.; también Kuhlen (1993), pp. 716 ss.

${ }^{21}$ Hefendehl (2002), pp. 159 ss. 
considerable. La "aptitud” únicamente cobraría relevancia si se declarara bien jurídico protegido a los medios del medioambiente mismo, es decir, animales y plantas.

\section{Accesoriedad administrativa}

1. Trazar la línea divisoria entre la explotación del medio ambiente autorizada y el daño prohibido al medio ambiente es algo que no puede hacer el derecho penal sino que constituye una genuina materia del derecho público. De ahí que el derecho penal del medio ambiente se caracterice por una llamada accesoriedad administrativa. Por esto es que a menudo se escucha decir: "Lo que está permitido en el derecho público no puede prohibirse en el derecho penal”22. A primera vista encontramos una problemática similar en la esfera de los delitos contra el patrimonio, en cuyo caso hablamos de una accesoriedad del derecho civil.

2. Empleo la expresión "a primera vista” porque en el ámbito del derecho penal del medio ambiente el problema especial que se divisa son las posibles agobiantes regulaciones que constituyen una carga para el medio ambiente, el cual precisamente carece de un intercesor directo. Aquí vale intervenir de modo correctivo, lo que entretanto ha hecho la legislación alemana.

Así, en el § 330d $\mathrm{N}^{0} 5$ StGB $^{23}$ se establece que también el actuar sobre la base de autorizaciones conseguidas capciosamente por medio de amenaza, cohecho o colusión, o mediante datos incorrectos o incompletos, ha de ser interpretado como un actuar sin autorización. Quien en semejante constelación se parapeta tras una autorización, actúa abusando del derecho y no puede en absoluto remitirse a haber actuado con la confianza de la conformidad a derecho de su conducta. Quedará por examinar si con ello las necesarias excepciones a la accesoriedad alcanzan una extensión suficiente.

\section{Punibilidad del funcionario: autoría y participación}

En Alemania, dada la ausencia de una normativa sobre la punibilidad de funcionarios (pese a las reiteradas demandas por tal normativa), la dogmática y la jurisprudencia han concebido caminos para disminuir los vacíos

\footnotetext{
${ }^{22}$ Por ejemplo en Breuer (1988), p. 2076 y Laufhütte y Möhrenschlager (1980), p. 919 .

${ }^{23}$ Introducido por la $2^{\text {a }}$ Ley para Combatir la Criminalidad Medioambiental (2. UKG) del 27.6.1994, Bundesgesetzblatt I S. 1440 (en Internet http://archiv.jura.unisaarland.de/cgi-bin/seiten.pl?jahr=1994\&teil=I\&seite=1440 [1. 7. 2008]).
} 
legales existentes ${ }^{24}$. Sin embargo, la autoría del funcionario público sólo es concebible en el caso de los llamados delitos comunes, aquellos, entonces, que pueden ser cometidos por cualquiera (§§ 324, 324a, 326, 328 I, II, IV, 329 III StGB). En el caso de los delitos especiales, bajo la figura de los llamados “delitos del explotador industrial” (§§ 325, 325a, 327, 328 III, 329 I, II StGB), no es posible construir una autoría para el funcionario externo. Aquí sólo queda la punibilidad a título de participación del funcionario público, que cesa, sin embargo, salvo en los casos del $\S 330 \mathrm{~d} \mathrm{~N}{ }^{0} 5$ StGB, en tanto no se presente, sobre la base de una autorización válida en términos del derecho administrativo, algún hecho principal antijurídico, y con ello susceptible de participación. Se han formado dos constelaciones fundamentales en las cuales cabe la punibilidad de funcionarios públicos, de acuerdo con los preceptos de las regulaciones de la Parte General del StGB.

1. En la primera constelación, el funcionario público concede dolosamente una autorización materialmente antijurídica pero formalmente válida para una conducta en sí imposible de ser autorizada.

a) aa) En caso de que el beneficiario de la autorización actúe de buena fe y con confianza en la legalidad de la autorización, el funcionario público ha de ser penalizado, de acuerdo con la jurisprudencia, como autor directo en el sentido del § 25 I Art. 2 StGB, por cometer el delito a través del beneficiario de la autorización como instrumento que actúa conforme a derecho. El funcionario público — a semejanza de un guardabarrera- levantaría la correspondiente "barrera jurídica" 25 para la realización del resultado típico, la que es “alzada” por dominio del hecho ${ }^{26}$. Mediante esto, en perspectiva del funcionario público y también objetivamente, el ilícito medioambiental puesto en marcha se presenta como "su obra"; él se convierte en la figura central del suceso como consecuencia de su perspectiva efectiva y jurídica.

bb) Pero con esto se confunden considerablemente los límites de la autoría (de la forma que sea), que han sido trabajosamente implementados

24 Tiedemann y Kindhäuser (1988), p. 345; Immel (1987), pp. 215 ss.; Proyecto del SPD para una $2^{\text {a }}$ Ley para Combatir la Criminalidad Medioambiental (2. OKG), Bundestags-Drucksache 12/376 pp. 27 ss. (en internet: http://dip.Bundestag.de/btd/12/ 003/1200376.pdf [1. 7. 2008]).

${ }^{25}$ Este tópico del "levantamiento de la barrera legal" fue establecido por Horn (1981), p. 4, sobre la base de un símil con el guardabarreras que levanta una barrera ferroviaria.

${ }^{26}$ Bundesgerichtshof [Corte Suprema Federal de Justicia] (1993), Horn (1994), p. 636, y Rudolphi (1994), p. 434 s., confirmado por el Bundesverfassungsgericht [Tribunal Constitucional Federal] (1995); conforme también Steindorf (1997b), Rn. 59. 
por la doctrina bajo el tópico del dominio de hecho ${ }^{27}$. De los casos de autoría mediata desarrollados, solamente cabría considerar aquel del dominio por conocimiento superior del "hombre de atrás", en virtud de un error del instrumento del delito. Aquí, algunos autores afirman el así llamado dominio por error del funcionario público ${ }^{28}$. Pero podríamos sumarnos a Wohlers en su crítica de que en verdad no se presenta en este caso un error excluyente del dolo por parte del beneficiario de la autorización, ni tampoco un error en relación con la antijuridicidad ${ }^{29}$. Independientemente de si la autorización tiene un efecto excluyente de la tipicidad o justificante, de acuerdo con la opinión vigente no depende de la conformidad material a derecho de la autorización sino que meramente de su vigencia formal ${ }^{30}$. Dado que en la presente constelación el beneficiario de la autorización solamente yerra respecto de la conformidad material a derecho de la autorización, se trata de un error de motivación jurídico-penal irrelevante respecto de circunstancias que se verifican al margen de la realización del delito. Y éste, por el contrario, no es capaz de fundamentar un dominio por conocimiento superior en virtud de error ${ }^{31}$. Además, ver en la comparación, más marcada por un gran valor metafórico que dogmático, con el alzamiento de una barrera por el guardabarrera ferroviario, una nueva forma, es decir, un nuevo caso de dominio del hecho, concedería a la autoría mediata un campo de aplicación demasiado extenso ${ }^{32}$. Si bien el funcionario tiene el dominio sobre la concesión de la autorización, el que se realice la acción perjudicial para el medio ambiente solamente está en manos de quien se beneficia con la autorización ${ }^{33}$. La lesión de un bien jurídico no parece absolutamente inevitable, pues el tren, por ejemplo, puede también detenerse. Hay que admitir, claro está, si se adopta la solución que recomienda la autoría mediata, que desde la solicitud de una autorización aparece altamente probable su posterior utilización.

b) aa) En el caso de mala fe del beneficiario de la autorización, la Corte Suprema Federal Alemana ha afirmado, en una interpretación extensiva, la coautoría en el sentido del § 25 Párrafo 2 StGB, en aquellos casos en que quien participa como beneficiario de la autorización tiene un interés

\footnotetext{
${ }^{27}$ Así también Schmitz (2006), Rn. 96 ss.

${ }^{28}$ Schall (1993), p. 721; dentro de ciertos límites también Schünemann (1986), p. 240.

${ }^{29}$ Wohlers (1996), pp. 71 ss.

${ }^{30}$ Véase infra E. II.

${ }^{31}$ Así también Schirrmacher (1995), p. 389 y Rudolphi (1982), p. 565.

${ }^{32}$ Cf. también Schünemann (1986), p. 240; Schirrmacher (1995), p. 389.

33 Michalke (1994), p. 1697; Schall (1993), p. 721; Otto (1991), p. 314; Breuer (1988), p. 2084.
} 
propio en el resultado. En el caso concreto, quiso hacer justicia a su fama de eficiente gestor de desechos ${ }^{34}$. En relación con el plan de acción conjunto entre funcionario público y beneficiario de la autorización, necesario para la coautoría, a la Corte Suprema Federal Alemana le basta con el acuerdo tácito que se desprende del dolo del representante del Estado y la mala fe de quien se beneficia de la autorización.

bb) Esto ha sido rechazado, y con razón ${ }^{35}$. De acuerdo con la interpretación absolutamente mayoritaria, es condición para un plan de acción conjunto que se llegue conscientemente a un recíproco concierto de voluntades de los respectivos partícipes del hecho ${ }^{36}$. La mera presencia paralela de mala fe por parte del beneficiario de la autorización y de dolo respecto a la antijuridicidad material de la autorización por parte del funcionario público no basta para una coautoría, aun cuando la mala fe ya hubiera existido durante la presentación de la solicitud.

2. En la segunda constelación, el funcionario omite proceder contra una afectación ilegítima del medio ambiente, que él también ha identificado como tal. Cabe considerar, entonces, la punibilidad por (autoría de) omisión de acuerdo al $\S 13$ del StGB. Aparte de los problemas descritos en la fundamentación de una comisión a título de autoría, es la posición de garante del funcionario del Estado la que constituye el problema decisivo.

a) Cabe primero pensar en una punibilidad a título de omisión en aquellos casos en que el actor no posee autorización alguna o excede una autorización (conforme a derecho) concedida y el funcionario público toma conocimiento de ello.

aa) Aquí, en parte, se supone una posición de garante general del funcionario competente, dado que las leyes administrativas medioambientales siempre y en todo caso deben proponerse también —aparte de una explotación adecuada — la protección del medio ambiente ${ }^{37}$. La Corte Suprema Federal Alemana también ha sancionado este punto en el caso de un alcalde de una localidad, eso sí que en un caso especial de contaminación de aguas en el marco de la evacuación de aguas residuales. La comuna, representada en la persona de su alcalde, cumplía aquí una especial posición de deber ${ }^{38}$. La pregunta por las condiciones bajo las que un funciona-

${ }^{34}$ Cf. Bundesgerichtshof [Corte Suprema Federal de Justicia] (1993), confirmado por el Bundesverfassungsgericht [Tribunal Constitucional Federal] (1995).

${ }^{35} \mathrm{Al}$ respecto Wohlers (1996), pp. 65 ss.

${ }^{36}$ Véase sólo Bundesgerichtshof (BGH) [Corte Suprema Federal de Justicia] (1985); Schünemann (2007b), Rn. 173 s.

${ }^{37}$ Cramer y Heine (2006), Rn. 39; Meinberg (1986), p. 223 y ss. y Steindorf (1997b), Rn. 64, en todo caso restrictivo en cuanto al concreto deber de garante, Rn. 65 ss.

${ }^{38}$ Bundesgerichtshof [Corte Suprema Federal de Justicia] (1992). 
rio público en general responde penalmente por la evitación de un resultado típico, fue expresamente dejada abierta por la Corte Suprema Federal Alemana.

bb) La aceptación de semejante posición de garante general parece en gran medida dudosa: no se presenta una acción contraria a deber precedente, de modo que se descarta una posición de garante por injerencia. Apenas convence una posición de garante tutelar abstracta del funcionario competente para la protección de los medios ecológicos administrados, pues de esta forma se impone al funcionario público un deber general de defensa de todos los bienes jurídicos del medio ambiente, lo que conduciría a una responsabilidad penal demasiado extensa ${ }^{39}$.

b) Paralelamente pueden darse casos en que el funcionario público competente omite revocar una autorización materialmente antijurídica (o que haya convertido en antijurídica).

aa) También los adversarios de una posición de garante general de los funcionarios consideran, en este caso, al funcionario competente como garante de tutela respecto a la administración del medio ecológico, debido a que a través de la autorización concedida se habría concretizado lo suficiente la posición de deber del funcionario público o de su sucesor ${ }^{40}$. En numerosas ocasiones también se supone una posición de garante por injerencia sobre la base de la concesión precedente, contraria al cuidado, de una autorización antijurídica ${ }^{41}$.

bb) No resulta convincente una posición de garante por injerencia en aquellos casos en que una autorización sólo deviene en antijurídica ${ }^{42}$. La injerencia en general representa de todos modos un cuerpo extraño en un sistema de posiciones de garante basado en el concepto de dominio ${ }^{43}$. Sin embargo, en términos generales ha de concederse que en comparación con los casos de un perjuicio "salvaje" existe aquí la diferencia de que se trata de un perjuicio que la autoridad ha autorizado y abarcado a través de su autorización materialmente antijurídica. En este caso, a lo menos, parece $54 \mathrm{~d}$.

${ }^{39}$ Sobre el particular véase Schünemann (1986), pp. 243 s.; Rudolphi (2000), Rn

40 Schünemann (1986), p. 244; Rudolphi (2000), Rn. 40 b; Steindorf (1997b), Rn. 64 con otras referencias; estableciendo diferencias, Schmitz (2006), Rn. 109, quien lo considera muy amplio. Lo correcto sería examinar en cada caso en particular si acaso de las leyes administrativas del medio ambiente se derivan deberes legales de control y vigilancia en cuanto a la evitación de delitos contra el medio ambiente por terceros; así también Kloepfer y Vierhaus (2002), Rn. 52.

${ }^{41}$ Al respecto Rudolphi (1994), p. 435; Schall (1993), p. 721; Steindorf (1997b), Rn. 57 con otras referencias; también Rogall (1991), pp. 208 ss.

${ }^{42}$ Rogall (1991), p. 208.

${ }^{43} \mathrm{Al}$ respecto Schünemann (1971), pp. 231 ss. 
posible una posición de garante tutelar suficientemente concretada. Debe exigirse, en forma restrictiva, que la discrecionalidad se reduzca a cero en cuanto a la revocación de la autorización de acuerdo con el §§ 48, 40 (L) VwVfG, es decir, que la autorización debería forzosamente revocarse de acuerdo con las regulaciones del derecho administrativo ${ }^{44}$.

c) De lege ferenda, se exige la introducción de un deber general legal de denuncia en caso de sospecha de un delito medioambiental, a fin de superar los déficits de cooperación de parte de la administración medioambiental en caso de delitos medioambientales graves ( $\S \S 330,330 \mathrm{a}$ StGB $)^{45}$, de modo similar a $\S 6$ de la Ley de Subvenciones. Esto tendría por consecuencia que, en el caso de una omisión de denuncia de un delito de esas características, el funcionario público se haría punible conforme al $\S 258$ a del StGB, por obstrucción a la justicia en el ejercicio de sus funciones. En algunos estados federados alemanes se introdujeron las respectivas obligaciones de denuncia bajo la forma de disposiciones administrativas ${ }^{46}$. Si bien esto no activa el § 258a del StGB, sí motivó al legislativo federal para no considerar una regulación legal en la $2^{\text {a }}$ Ley de Criminalidad del Medio Ambiente (UKG) ${ }^{47}$. En consideración al hecho de que el deber de denuncia bajo la forma de disposiciones administrativas no condujo a una suficiente disposición de denuncia por parte de las autoridades administrativas, el deber impuesto por ley parecería ser una posibilidad, al menos en los casos de graves daños al medio ambiente (§§ 330, 330a StGB), para mejorar la falta de cooperación con los tribunales, lamentada por todos los sectores ${ }^{48}$.

\section{El destinatario de la sanción}

1. Precisamente en los ámbitos del derecho penal económico y del derecho penal del medio ambiente, a menudo se ha planteado en Alemania la exigencia de establecer como destinatario de una sanción a la organización misma ${ }^{49}$. Como motivo de aquello se invocan con frecuencia las vulneraciones de bienes jurídicos cometidas desde empresas, que muchas veces no son individualmente imputables. Estos son puntos de vista pragmáticos, los que hasta ahora no ha seguido el Código Penal alemán. Más bien se sostiene aquí un sistema de varias vías. En el centro se alza la responsabili-

${ }^{44}$ Schmitz (2006), Rn. 113; Ransiek (2005b), Rn. 70.

${ }^{45}$ Véase, por ejemplo, Schall (1990), pp. 1272 ss.

${ }^{46}$ Véase Kloepfer y Vierhaus (2002), Rn. 46 con referencias adicionales.

${ }^{47}$ Bundesrats-Drucksache [Publicación de la Cámara Alta Federal]: Resolución oficial, 126/90, p. 35.

${ }^{48}$ Otra opinión, especialmente voces provenientes de la literatura sobre derecho administrativo, tal como Breuer (1990), pp. 477 s., 487.

${ }^{49}$ Ransiek (2005a), Rn. 31, 35 ss. con referencias adicionales. 
dad individual acorde con el StGB, en que vía el § 14 StGB son trasferidas al representante características personales especiales a fin de poder cerrar de este modo vacíos de punibilidad. Una imputación aligerada se puede encontrar también en el $\S 130$ OWiG para el caso de infracción de un deber de vigilancia del titular empleador y el § 30 OWiG prevé una multa para la organización.

2. De acuerdo con la opinión todavía dominante en Alemania, es el principio de culpabilidad el factor de freno decisivo para la introducción de la punibilidad de organizaciones, muy a pesar de los más refinados intentos por desarrollar construcciones dogmáticas ${ }^{50}$. Entretanto, un número cada vez mayor de Estados del continente europeo han tirado generosamente por la borda semejantes consideraciones y convertido a personas jurídicas en posibles autores de un delito ${ }^{51}$. También a nivel del derecho europeo hay tendencias manifiestas en esa dirección por parte de la UE ${ }^{52}$.

\section{Diversificación de las sanciones}

Hoy en día se reflexiona intensamente en torno a ampliar el clásico arsenal de sanciones que contempla el Derecho Penal, especialmente la pena privativa de libertad y la multa, a fin de incrementar los efectos preventivos. En este caso no cabe pensar sólo en confiscación y caducidad de la patente, sino que también en el establecimiento de la figura del delegado de la empresa en el derecho del medio ambiente ${ }^{53}$. En los proyectos de reforma chilenos se contemplan, por ejemplo, las sanciones de prohibición del ejercicio de la profesión, la momentánea suspensión de faenas y la disolución de la persona jurídica.

\section{F. ¿Hacia dónde debe ir el viaje? Conclusiones del análisis}

Este análisis de las líneas fundamentales chilenas y alemanas en el derecho penal del medio ambiente nos coloca en posición de sacar conclusiones importantes para los requerimientos de una reforma.

${ }^{50}$ Así también Schmitz (2006), Rn. 129; Winkelbauer (1998), pp. 646 s.

${ }^{51}$ Por ejemplo, Francia, los Países Bajos, los países escandinavos y Suiza; en Italia y en Austria existen — como ahora en Chile- proyectos de ley al respecto; véase, sobre todos, Schünemann (2007a), Rn. 20 con referencias adicionales; Mittelsdorf (2007), p. 90.

${ }^{52}$ Fromm (2007), pp. 279 ss.

${ }^{53}$ La designación de semejante delegado de la empresa está ya prevista, por ejemplo, en el § 21 a de la Ley de Régimen Hidráulico (WHG), o en el § 53 de la Ley Federal para la Protección contra las Emisiones (BImSchG). 


\section{Un ecocentrismo moderado con repercusiones para la dogmática}

1. Por ecocentrismo moderado entiendo un punto de vista que toma en serio el valor autónomo del medio ambiente, pero ahora, igual que antes, considera relevante la relación con los seres humanos. Esta relevancia, sin embargo, es aligerada de una doble manera: por una parte, por la remisión a las futuras generaciones, por otra parte, por una especie de inversión de la carga de la prueba, que también se nutre de los alarmantes avances en el conocimiento entregado por las ciencias. A lo anterior debería ser absolutamente excepcional la esperanza de que la fuerza autocurativa de la naturaleza será capaz de revertir un daño al medio ecológico hasta el punto de que pareciera no causado, quedando descartada la posibilidad de influencia negativa sobre el ser humano. Esto podrá afirmarse, en el mejor de los casos, en referencia a bagatelas, las cuales cabe ya excluir del tipo por ausencia de relevancia.

2. Consecuentemente, para ese punto de vista, con la aparición del resultado ya está también realizado el daño. De modo que tenemos un delito de lesión. A mí también me parece indicada tal simplificación, por el hecho de que con la interpretación como delito de peligro abstracto no se gana en potencia crítica. Además — como ya se ha explicado— la estructura de delito relacionada del delito de aptitud, empleada tanto en Alemania como en Chile, sería consistentemente aplicable.

3. La estrecha sujeción en el Código Penal chileno de los delitos contra el medio ambiente a clásicos delitos protectores de bienes jurídicos individuales, suena como una reminiscencia de la así llamada Escuela de Francfort alemana que apuesta a los bienes jurídicos individuales y condena los bienes jurídicos colectivos ${ }^{54}$. A mi juicio, sin embargo, los bienes jurídicos medioambientales equivalen a una categoría de bienes jurídicos igualmente legítimos porque no controlan “desde arriba” a los miembros de una sociedad sino que generan para éstos oportunidades de vida "desde abajo”55. Mientras menos excepciones se generen para los económicamente poderosos, tanto mejor podrá realizarse la meta de un Derecho Penal para los individuos. Uno debe separar la protección de los recursos de la protección de los bienes jurídicos individuales clásicos.

\footnotetext{
${ }^{54}$ Hassemer (1992), p. 383; Herzog (1991), pp. 188 ss., 196 ss.; Hohmann (1992), pp. 76 ss.

${ }^{55}$ Hefendehl (2006b), p. 232 ss.; del mismo (2006c), p. 457; contra la propuesta de retroceso del derecho penal del medio ambiente por la Escuela de Francfort, también Schünemann (1995), pp. 201 ss.
} 


\section{Norma modelo}

1. Cabe distinguir entre dos modelos para la construcción del derecho penal ${ }^{56}$ : si se interpreta el comportamiento cuestionable típicamente como injusto merecedor de pena, entonces la autorización por parte de la autoridad no toca el tipo y actúa meramente en forma (excepcionalmente) justificante. Se habla aquí de una prohibición represiva con reserva de liberación. El delito de la contaminación de aguas está estructurado en Alemania acorde con este modelo, según el § 324 StGB, que dice: “Quien contamina las aguas sin estar autorizado...”. También pertenece aquí otro tipo penal preponderantemente representado en la estadística policial, aquel del manejo no autorizado de residuos peligrosos según el § 326 StGB.

2. En el caso de que la conducta cuestionable sea considerada por principio como digna de aprobación o valóricamente neutral porque la utilización de recursos se relaciona con la producción de bienes económicos, la autorización misma ya excluye la tipicidad. Desde una perspectiva jurídica administrativa, se trata de un modelo de prohibición preventiva con reserva de permiso. A este grupo pertenecen aquellos tipos penales que prevén una acción "con infracción de deberes jurídico-administrativos”, como por ejemplo, la contaminación del aire, conforme al § 325 StGB.

3. En mi opinión, también por razones simbólicas, todo habla a favor de tomar como norma modelo al tipo penal de contaminación de aguas ${ }^{57}$. Pues, aquello que en nuestra economía social de mercado se contempla como "valor socialmente digno de aprobación", ya no es en absoluto suficiente para ejercer, ni siquiera aproximadamente, una protección bastante de los bienes jurídicos. También la protección del aire, por ejemplo, puede estructurarse de este modo. Actividades permitidas de forma general, como, por ejemplo, el tráfico vehicular y la calefacción doméstica, estarían justificadas aquí sobre la base de la adecuación social, siempre y cuando en ello se mantengan los valores máximos de emisión de contaminantes autorizados, o todavía por ser autorizados. En Alemania y según el § 325 V StGB, quedan en la actualidad totalmente excluidos como medios delictivos los vehículos motorizados y los medios de transporte ferroviario, aéreo y naviero. Mediante semejante norma modelo también se eliminaría el característico desequilibrio, de acuerdo con el cual la evacuación indebida del aceite automotor quemado de un solo vehículo motorizado importa siempre un injusto merecedor de pena, no en cambio la destrucción de recursos, en principio eficiente desde el punto de vista económico pero dramática desde el punto

\footnotetext{
${ }^{56} \mathrm{Al}$ respecto, también Schmitz (2006), Rn. 42 ss.

${ }^{57}$ En este sentido, también Schünemann (1996), p. 454.
} 
de vista ecológico. Por ello el derecho penal del medio ambiente debe entonces ayudarse del derecho administrativo para hacerse cargo tanto del consumo normal por parte del ciudadano como del de la economía, castigando el consumo excesivo y reaccionando en el caso de accidentes.

\section{La relación entre derecho penal y derecho administrativo}

Previamente se ha descrito la doctrina dominante en el derecho penal del medio ambiente. Salvo unas pocas excepciones, ella ha extendido la idea de la accesoriedad hacia una accesoriedad del acto administrativo. Esto significa: un acto administrativo vinculante, posiblemente también antijurídico, es capaz de impedir la aplicación del derecho penal del medio ambiente. Si bien con esto se alcanza una armónica conciliación entre el derecho penal y el derecho administrativo en el sentido de "la unidad del ordenamiento jurídico”, el costo de la misma lo paga el medio ambiente. Sin poder referirme aquí a ello con detalle, más bien quisiera solamente, al igual que Schünemann, abogar por el carácter determinante del derecho administrativo, es decir, privar a las autorizaciones contrarias a derecho de la capacidad de eliminar la antijuridicidad ${ }^{58}$. La construcción formal del derecho administrativo, que también trata con actos administrativos vinculantes pero antijurídicos, no tendría, entonces, ninguna relevancia en la protección de bienes jurídicos asegurados constitucionalmente a través del Art. 20 de la Ley Fundamental alemana. Los cuestionamientos comúnmente aducidos contra semejantes reflexiones, en el sentido de que al ciudadano se le privaría de toda certeza jurídica, caerían en el vacío por el hecho de que la confianza en la juridicidad de una autorización seguiría siendo, fundamentalmente, digna de protección también en el marco de este modelo ${ }^{59}$. Pero privaría a aquellos que toman parte en la destrucción del medio ambiente de la posibilidad de parapetarse, por así decir, tras la obligatoriedad de un acto administrativo.

\section{Problemas de autoría}

1. Las reflexiones hasta aquí expuestas han mostrado lo siguiente: en la protección del medio ambiente no se trata de la protección de la Administración del Estado, sino de bienes jurídicos ecológicos en sí mismos. El pasaje del Foro Penal que enfatiza la protección penal del sistema administrativo debe ser mirado con escepticismo. Por eso también se descarta el motivo para restringir el círculo de autoría a personas especialmente califica-

\footnotetext{
${ }^{58}$ Schünemann (1996), pp. 442 ss.; véase también Schall (1990), pp. 1266 ss.

${ }^{59}$ Schünemann (1996), p. 447.
} 
das, como el encargado de una industria. Como Schünemann subrayara hace ya diez años, con relación a las cuestiones de autoría también puede interpretarse como norma modelo el tipo penal de la contaminación de aguas. Autor debiera ser, entonces, aquel que tenga el dominio del hecho sobre un acontecimiento que conduce al daño para el medio ambiente. Para estos efectos no juega ningún rol que el que domine el acontecimiento en calidad de autor mediato sea el dueño de la empresa, un trabajador o el funcionario público de la autoridad estatal a cargo de las aguas ${ }^{60}$.

2. Las sanciones contra la empresa misma no sólo son intensamente discutidas con relación al Derecho Penal chileno, sino que en muchas ocasiones ya se encuentran en práctica ${ }^{61}$. Me gustaría aquí discutirlas pragmáticamente, teniendo como fondo un efecto preventivo mejorado ${ }^{62}$.

a) Un modo evidente de contemplar el asunto concluiría de forma aparentemente imperativa, especialmente a partir de las peculiaridades sociológicas del “corporate crime”, que éste debiera ser, entonces, el destinatario de la sanción. Claro que visto contra el trasfondo de los déficits de control mediante el derecho, no me parece que con ello se ganaría nada decisivo. Meramente se verían mermados los presupuestos de imputación dogmáticos, pues éstos, en cierto modo, se frenarían ante la empresa en cuanto sistema. Uno podría en todo caso suponer que mejoraría la calidad de la información en la organización en cuanto destinatario, pero al mismo tiempo también habría que ponderar que las informaciones estén repartidas al interior de la organización. A ello se suma que las técnicas de neutralización al interior de una empresa actúan hasta llegar a una actitud criminal de asociación ${ }^{63}$.

b) Aparece entonces pragmático que si bien las posibilidades de sanción a organizaciones reducen los problemas de persecución, no se alcanzarían mejores efectos de prevención. En esa perspectiva, me parece que el precio de las condiciones básicas esenciales del derecho penal es sencillamente demasiado alto. Se tiraría por la borda, por así decirlo, el principio de culpabilidad, sin obtener nada a cambio.

\section{En busca de otras sanciones, es decir, de una intensificación de la persecución}

Precisamente esa deficiente eficacia preventiva de una punibilidad de las organizaciones ha venido forzando desde hace un tiempo las demandas en pos de otras sanciones y medidas; en particular se han escuchado

\footnotetext{
60 Schünemann (1996), p. 455.

61 Véase supra E. IV. 2.

${ }^{62}$ Hefendehl (2007), pp. 834 ss.

${ }^{63}$ Véase, por ejemplo, Mittelsdorf (2007), pp. 43 ss.
} 
fuertes demandas por una intensificación de la persecución. Me he referido a este aspecto ya en otra parte ${ }^{64}$, de modo que aquí sólo enunciaré algunas ideas clave.

1. a) Debe distinguirse entre las siguientes tres formas de sanción: en un primer grupo de estas formas de sanción más recientes deben catalogarse aquellas que en caso de una conducta delictual económica amenazan con desventajas competitivas. Aquí figuran, por ejemplo, la publicación de sentencias en el sentido de un efecto de "picota” (Prangenwirkung) ${ }^{65}$, las ya mencionadas prohibiciones de actividad, o la revocación de autorizaciones. Las sanciones de un segundo grupo apuntan a privar a la empresa de su autonomía mediante un control externo o interno. Entre éstas se cuentan la vigilancia mediante curatela ${ }^{66}$, o el nombramiento de encargado de la empresa, o bien el arrendamiento forzado de las instalaciones. En el tercer grupo de sanciones se ha de privar a los autores de los beneficios del acto ilícito. Cabe aquí mencionar la confiscación, el comiso y la destrucción de los productos obtenidos mediante el ilícito ${ }^{67}$.

En Estados Unidos, el difundido “private law enforcement” y la institución del "whistleblowing” deben darle validez al derecho; junto con ello existe, además, la tendencia a compensar los problemas de control en el derecho con medidas de la llamada prevención situacional. Para nombrar algunos ejemplos: los requerimientos para obtener autorización para participar en el mercado son parte de ella, del mismo modo como lo son el popular “profiling” para la contratación por parte de las empresas. Medidas laborales afines como la división de funciones entre los trabajadores, el principio del "need-to-know" la rotación laboral, la exigencia de registrar hora de ingreso y salida o la videovigilancia también contribuyen a incrementar el costo de una conducta criminal.

b) Finalmente, en Europa son cada vez más populares las medidas que tienden a transformar el control a través del derecho en un control mediante "governance". Sin embargo, en mi opinión, hasta el momento no se ha demostrado que la cúpula empresarial tome, en absoluto, conocimiento de esto ${ }^{68}$.

2. Estos ámbitos totalmente diferentes, paralelos a un derecho penal del medio ambiente, muestran el espectro de estrategias de combate que

\footnotetext{
${ }^{64}$ Hefendehl (2007), pp. 828 ss.

${ }^{65}$ La llamada publicidad negativa; véase al respecto Schwind (2008), § 22 Rn 39.

${ }^{66}$ Demandado por Schünemann (1994), pp. 290 s.

${ }^{67} \mathrm{Al}$ respecto Schall y Schreibauer (1996), p. 441.

${ }^{68}$ Cf. las reserves formuladas por Hefendehl (2007), pp. 844 ss.
} 
existen. Aquí nos limitaremos a enfatizar solamente una cosa: las medidas extra-penales no son en todos los casos menos intensas en su intervención que el derecho penal y deben ser sometidas a un examen de proporcionalidad. Éste revelará que posiblemente los modelos alternativos muestran una mayor eficacia preventiva que el derecho penal, pero que el alcance de su intervención podrá en parte ser todavía más profundo.

\section{VI. ¿Protección del medio ambiente a través del derecho administrativo, del derecho penal o de lo simbólico?}

¿Pero que ocurriría si la mayor eficiencia de cualquier norma de sanción no sirviera de nada, debido a que el 99,9\% de la destrucción ambiental estuviera legalizada? ¿Deberíamos entonces renunciar al derecho penal y apostarlo todo al derecho administrativo? Porque el derecho penal no hace más que preocuparse de la punta del iceberg y porque semejante derecho penal simbólico ${ }^{69}$ es más bien una solución aparente y distrae de las verdaderas tareas.

1. En los hechos, el derecho administrativo dispone entretanto de una multiplicidad de instrumentos de regulación. Si se establecen diferencias acordes con la forma de actuar sobre los destinatarios, es posible distinguir seis grupos ${ }^{70}$ :

a) El primer grupo lo forman los instrumentos de planificación. Como parte de una estructuración previsora del medio ambiente, a la planificación del medio ambiente le cabe una importancia determinante. En Alemania, esa planificación se realiza esencialmente a través de planificaciones por rubros individuales, reguladas por una legislación especial de la cual forman parte, por ejemplo, la Ley Federal para la Protección de la Naturaleza (BNatSchG), la Ley de Régimen Hidráulico (WHG), la Ley Federal para la Protección contra Emisiones (BImSchG). Estas leyes también son crecientemente determinadas por normativas de la Comunidad Europea, especialmente por la directriz para el estudio de tolerancia medioambiental estratégico, de acuerdo con la cual determinados planes y programas deben ser sometidos a un estudio de tolerancia medioambiental. Expresiones de semejante planificación del medio ambiente son, por ejemplo, la planificación paisajística, la identificación de áreas protegidas y la creación de planes de explotación.

b) Al segundo grupo pertenecen los instrumentos del control conductual directo, que en el sentido de un derecho (de control) medioambien-

${ }^{69} \mathrm{Al}$ respecto véase también Ripollés (2001), pp. 528 ss.

${ }^{70}$ Cf. Kloepfer (2004), § 5 Rn. 7 y ss.; Sparwasser, Engel y Voßkuhle (2003), § 2 Rn. 57 ss. 
tal contienen, a fin de cuentas, un “imperativo” que ordena o prohíbe. Pueden ser instrumentos de control administrativo ${ }^{71}$, imposiciones o prohibiciones legales directas, así como deberes legales individuales para con el medio ambiente ${ }^{72}$.

c) En la tercera categoría pueden clasificarse instrumentos de control conductual indirecto que no contengan pautas de comportamiento directas y vinculantes, sino que cobran influencia sobre el destinatario vía mecanismos indirectos, mediatos. En primer lugar cabe pensar aquí en incentivos financieros, ya sea en el plano de la “premiación”, como son el otorgamiento de ventajas, o mediante subvenciones directas o indirectas, $\mathrm{y}$, por otra parte, en una perspectiva “punitiva”, que impone impuestos medioambientales a las conductas lesivas para el medio ambiente. Otro medio políticojurídico sumamente actual en el contexto del Protocolo de Kioto son las llamadas soluciones de certificación. Consisten en el otorgamiento de licencias medioambientales o “derechos de emisión” posibles de ser transados, equivalentes a una contaminación máxima del medio ambiente autorizada, lo que conduce a que en forma acorde con la oferta y la demanda se va constituyendo un precio de mercado que torna las inversiones en la preservación del medio ambiente económicamente rentables y está destinado a evitar las emisiones allí donde resulta más conveniente.

d) Dado que en el presente ya no es posible lograr una protección efectiva del medio ambiente sin la suficiente información medioambiental, los instrumentos informativos, como prevenciones y recomendaciones, componen el cuarto grupo de los instrumentos del derecho del medio ambiente. Por una parte, el Estado requiere de informaciones sobre las interrelaciones del medio ambiente y sobre el estado del mismo como base para la protección estatal del medio ambiente. Por otra parte, el ciudadano en cuanto consumidor tiene gran necesidad de información. Con esta finalidad se le transmite al ciudadano información sobre las interrelaciones del medio ambiente, la tolerancia del medio ambiente a productos o modos de comportamiento, por vía de recomendaciones estatales, prevenciones e indicaciones, es decir, se le conceden al ciudadano derechos de acceso a información.

e) El quinto grupo lo componen instrumentos de organización empresarial. Ellos se deben al reconocimiento de que es especialmente en las empresas donde una protección del medio ambiente que apuesta únicamen-

${ }^{71}$ Deber de denuncia, deber de registro, reserva de permiso, autorización de interdicción y atribuciones de vigilancia.

72 Por ejemplo, deberes de cuidado, deberes de explotación y conservación, deberes de vigilancia y aseguramiento, o deberes de tolerancia o intervención. 
te a medios de vigilancia e imperativos encuentra sus limites. De ahí que se implementen instrumentos de organización empresarial. A éstos pertenecen instrumentos coercitivos, de ejercicio directo del control, como los deberes legales de información pública y de organización, especialmente para la designación de un encargado para la protección del medio ambiente, con la finalidad de supervisar el cumplimiento al interior de la empresa de la legislación medioambiental y para establecer "como objetivo de la empresa” a ser integrado, la protección del medio ambiente. Conjuntamente con los anteriores cuentan aquí los instrumentos de control indirecto, a los que apuestan las empresas de propia iniciativa, como, por ejemplo, la llamada auditoría medioambiental. Aquí se trata del establecimiento autónomo de políticas, medios y programas empresariales de medio ambiente, así como de sistemas de gestión medioambiental efectivos, que posteriormente son sometidos a exámenes periódicos externos. Con esto se busca fortalecer la responsabilidad de la propia industria en la superación de las consecuencias medioambientales de su actividad, y avanzar hacia la desregulación del derecho medioambiental vigente.

f) Finalmente, el sexto grupo se constituye a partir de instrumentos de cooperación, para el cual también se ha generalizado en la literatura el concepto de convenios medioambientales. Aquí se renuncia a toda coerción estatal y en su lugar se activa la iniciativa privada. Aparte de contratos genuinos (tanto de derecho público como de derecho privado) con efecto jurídico inmediato, entre estos instrumentos también se cuentan los convenios informales. Su gestión no está ni atada a determinados presupuestos jurídicos, ni emanan de ellas — de acuerdo con la opinión mayoritariaefectos jurídicos directos. También el instrumento de la tolerancia por las autoridades, que en el marco del derecho penal del medio ambiente es discutido de modo controvertido ${ }^{73}$ con relación a su efecto de legalización, forma parte de este grupo.

2. Ahora bien, acaso en consideración a estos instrumentos administrativos realmente se debiera renunciar al derecho penal es algo sobre lo que hay posiciones muy diversas: la antes mencionada Escuela de Francfort lo ha demandado de modo provocador ${ }^{74}$, mientras que Schünemann sostiene que una crítica tan radical del derecho penal del medio ambiente es algo equivocado y verdaderamente reaccionario ${ }^{75}$. De lo contrario se renunciaría por completo, en el terreno de la ecología, a la finalidad de la pena de la prevención general positiva.

${ }^{73}$ Véase, por ejemplo, Steindorf (1997a), Rn. 44 ss.

${ }^{74}$ Hassemer (1992), p. 383; Herzog (1991), pp. 141 ss.; Hohmann (1992), pp. 76 ss.

${ }^{75}$ Schünemann (1995), pp. 203 ss. 
3. a) Mediante el concepto del "governing through crime" hoy se describe cada vez más la instrumentalización de la criminalidad y de la política criminal con fines de poder político ${ }^{76}$. El carácter explícitamente funcional de esta política so pretexto de objetivos apócrifos tal vez puede hoy en día visualizarse en la criminalidad económica o en la forma de proceder contra los llamados abusadores de menores. Pero yo más bien sumaría el derecho penal medioambiental a una política simbólica de apaciguamiento. Si se renunciara al derecho penal en este último ámbito, después de haberse luchado durante décadas por su integración al derecho penal nuclear, en mi opinión se lograría tan sólo un destello exclamativo, un grito fugaz. En el largo plazo quedaría la extrañeza ante el hecho de por qué en tiempos de una intensa, aunque casi siempre inconducente, discusión en torno de la ecología ya no hay un derecho penal conexo, especialmente cuando se ha calificado a los bienes jurídicos protegidos como elementales para el ser humano.

b) De modo que si el Estado quiere conservar su credibilidad y defender el principio de igualdad, deberá entonces establecer una delimitación plausible y persistente entre la utilización permitida del medio ambiente y el daño punible al medio ambiente, y realizar cambios en la materia. Mientras sigamos constatando que contra el mencionado 99,9\% de destrucción actual del medio ambiente no se puede hacer nada, incluso en presencia de una cuota de esclarecimiento perfecta, el derecho penal del medio ambiente seguirá siendo tan sólo una "hoja de parra”*. No hará daño, claro, pero tampoco traerá nada.

\section{G. Resumen}

Esta breve revisión de los límites de la criminología, la dogmática y la política criminal en base a ejemplos de bienes jurídicos penales que no sólo son importantes sino, más aún, elementales y vitales para la supervivencia, muestra que en este terreno vale la pena una intensa reflexión. El proceso chileno de reforma del derecho penal del medio ambiente se encuentra en marcha. Existe la oportunidad de evitar los errores de otros ordenamientos de derecho penal y de sentar nuevos impulsos. Sin embargo, se trata de un cometido muy difícil, dado que un mejor derecho penal del medio ambiente

${ }^{76}$ Véase el título de la monografía de Simon (2007) del mismo nombre.

* La expresión "hoja de parra" en alemán, corresponde en su uso metafórico a un objeto puesto frente a otro, con el fin de ocultarlo, para no revelar la cualidad moral atacable del objeto oculto, en un sentido similar al relato bíblico de Adán y Eva. [N. del T.] 
debería tomar conciencia de la responsabilidad frente a futuras generaciones y, posiblemente, también asumir las desventajas competitivas en una competencia globalizada. Semejante responsabilidad está arraigada en la Carta Fundamental alemana. Aquí, como también en otros Estados, a la política casi siempre le falta el largo aliento para empeñarse sostenidamente en esto. La ciencia penal no debiera callar al respecto, pero no debiera ser ingenua. En un cuento infantil alemán llamado "Los Músicos de la Ciudad de Bremen” puede leerse la frase siguiente: “Transita mejor conmigo, dijo el burro, por doquier puedes hallar algo mejor que la muerte”. Es un hecho que deberíamos ponernos en marcha. La situación actual significa la muerte mencionada. Tal vez no para nosotros, pero sí para las generaciones venideras.

\section{BIBLIOGRAFÍA}

Breuer, Rüdiger (1990): "Probleme der Zusammenarbeit zwischen Verwaltung und Strafverfolgung auf dem Gebiet des Umweltschutzes”. En Archiv des öffentlichen Rechts (AöR), pp. 448-488.

- (1988): "Empfehlen sich Änderungen des strafrechtlichen Umweltschutzes insbesondere in Verbindung mit dem Verwaltungsrecht?”. En Neue Juristische Wochenschrift (NJW), pp. 2072-2085.

Bundesgerichtshof (BGH) [Corte Suprema Federal de Justicia] (1993): Urteil, 03/11/1993, 2 StR 321/93. En internet: http://www.hrr-strafrecht.de/hrr/2/93/2-321-93.php? referer=db [1.7.2008].

(1992): Urteil, 19/08/1992, 2 StR 86/92. En Neue Juristische Wochenschrift (NJW), pp. 3247-3251.

(1985): Beschluss, 02/10/1984, 4 StR 551/84. En Neue Zeitschrift für Strafrecht (NStZ), pp. 70-71.

Bundeskriminalamt (BKA) (2006): "Polizeiliche Kriminalstatistik”. En internet: http:// www.bka.de/pks/pks2006/index2.html [1.7.2008].

Bundesministerium des Inneren und Bundesministerium der Justiz (BMI und BMJ) (2006): “Zweiter Periodischer Sicherheitsbericht”. En internet: http://www.bmj.bund.de/ enid/Studien_Untersuchungen_und_Fachbuecher/2_Periodischer_Sicherheitsbericht_14d.html [1.7.2008].

Bundesrats-Drucksache [Publicación de la Cámara Alta de la República Federal], Resolución oficial, 126/90, p. 35.

Bundestags-Drucksache [Publicación del Parlamento Alemán], Considerando oficial, 8/ 2382.

Bundesverfassungsgericht (BVerfG) (1995): Beschluss, 04/10/1994, 2 BvR 322/94. En Neue Juristische Wochenschrift (NJW), pp. 186-178.

Cramer, Peter y Günter Heine (2006): “Vorbem §§ 324 ff. StGB”. En Schönke/Schröder Kommentar Strafgesetzbuch. Munich: C. H. Beck, vigésimosexta edición.

Eisenberg, Ulrich (2005): Kriminologie. Munich: C. H. Beck, sexta edición. 
Europäische Kommission [Comisión Europea] (2007): Vorschlag für eine Richtlinie über den strafrechtlichen Schutz der Umwelt, 09/02/2007. En internet: http://europa.eu/ $\mathrm{rapid} /$ pressReleasesAction.do?reference=MEMO/07/50\&format=PDF\&aged= 1\&language $=$ EN\&guiLanguage $=$ en [1.7.2008] .

(2006): Verzeichnis der Umweltverschmutzung durch kleine oder nichtindustrielle Verursacher, 18/09/2006. En internet: http://europa.eu/rapid/ pressReleasesAction.do?reference=IP/06/1204\& format=HTML\&aged $=1 \&$ language $=\mathrm{DE} \&$ guiLanguage $=\mathrm{en}$ [1.7.2008].

Europäischer Gerichtshof (EuGH) (2005): Urteil, Kommission der Europäischen Gemeinschaften gegen Rat der Europäischen Union, 13/09/2005, C 176/03. En internet: http://eurlex.europa.eu/LexUriServ/LexUriServ.do?uri=CELEX:62003 J0176:EN:HTML [1.7.2008].

Fromm, Ingo (2007): "Auf dem Weg zur strafrechtlichen Verantwortlichkeit von Unternehmen/Unternehmensvereinigungen in Europa?”. En Zeitschrift für internationale Strafrechtsdogmatik (ZIS), pp. 279-291. Artículo en internet: http:/ /www.zis-online.com/dat/artikel/2007_7_148.pdf [1.7.2008].

Hassemer, Winfried (1992): "Kennzeichen und Krisen des modernen Strafrechts". En Zeitschrift für Rechtspolitik (ZRP), pp. 278-383.

Hecker, Bernd (2003): "Die Strafbarkeit grenzüberschreitender Luftverunreinigungen im deutschen und europäischen Umweltstrafrecht”. En Zeitschrift für die gesamte Strafrechtswissenschaft (ZStW), pp. 880-905.

Hefendehl, Roland (2007): "Außerstrafrechtliche und strafrechtliche Instrumentarien zur Eindämmung der Wirtschaftskriminalität”. En Zeitschrift für die gesamte Strafrechtswissenschaft (ZStW), pp. 817-847.

- (2006a): "Europäischer Umweltschutz: Demokratiespritze für Europa oder Brüsseler Putsch?”. En Zeitschrift für internationale Strafrechtsdogmatik (ZIS), pp. 161-167. Artículo en internet: http://www.zis-online.com/dat/artikel/ 2006_4_25.pdf [1.7.2008].

(2006b): “Europäisches Strafrecht: bis wohin und nicht weiter?”. En Zeitschrift für internationale Strafrechtsdogmatik (ZIS), pp. 229-236. Artículo en internet: http://www.zis-online.com/dat/artikel/2006_6_36.pdf [1.7.2008].

(2006c): “European Criminal Law: How Far and No Further?”. En Bernd Schünemann (ed.), A Programme for European Criminal Justice, pp. 450-466. Colonia, Berlín, Munich: Heymanns.

- (2005): "Neutralisationstechniken bis in die Unternehmensspitze". En Monatsschrift für Kriminologie und Strafrechtsreform (MschrKrim), pp. 444-458.

- (2004): "Die Strafvorschriften im Naturschutzrecht - oder: Warum das Strafrecht für den Schutz der Natur nicht prädestiniert ist”. En Detlef Czybulka (ed.), Wege zu einem wirksamen Naturschutz: Das neue BNatSchG - Analyse und Kritik, pp. 238-263. Baden-Baden: Nomos.

(2003): "Kriminalitätstheorien und empirisch nachweisbare Funktionen der Strafe: Argumente für oder wider die Etablierung einer Unternehmensstrafbarkeit?”. En Monatsschrift für Kriminologie und Strafrechtsreform (MschrKrim), pp. 27-43. (2002): Kollektive Rechtsgüter. Colonia: Heymanns.

(2001): "Die Strafvorschriften im Naturschutzrecht - oder: Warum das Strafrecht für den Schutz der Natur nicht prädestiniert ist”. En Natur und Recht (NuR), pp. 498-506. 
Herzog, Felix (1991): Gesellschaftliche Unsicherheit und strafrechtliche Daseinsvorsorge. Heidelberg: v. Decker.

Hohmann, Olaf (1992): "Von den Konsequenzen einer personalen Rechtsgutbestimmung im Umweltstrafrecht”. En Goltdammer's Archiv für Strafrecht (GA), pp. 76-87.

Horn, Eckhard (1994): "Strafrechtliche Verantwortung von Amtsträgern für die Genehmigung umweltgefährdender Projekte”. En Juristenzeitung (JZ), p. 636. - (1981): "Strafbares Fehlverhalten von Genehmigungs- und Aufsichtsbehörden?”. En Neue Juristische Wochenschrift (NJW), pp. 1-11.

Immel, Burkhard (1987): Strafrechtliche Verantwortlichkeit von Amtsträgern im Umweltstrafrecht: Umweltuntreue. Francfort del Meno: Lang.

Kloepfer, Michael (2004): Umweltrecht. Munich: C. H. Beck, tercera edición.

Kloepfer, Michael y Hans-Peter Vierhaus (2002): Umweltstrafrecht. Munich: C. H. Beck, segunda edición.

Kuhlen, Lothar (1993): "Umweltstrafrecht - auf der Suche nach einer neuen Dogmatik". En Zeitschrift für die gesamte Strafrechtswissenschaft (ZStW), pp. 697-726.

Laufhütte, Heinrich y Manfred Möhrenschlager (1980): “Umweltstrafrecht in neuer Gestalt”. En Zeitschrift für die gesamte Strafrechtswissenschaft (ZStW), pp. 912972.

Meinberg, Volker (1986): “Amtsträgerstrafbarkeit bei Umweltbehörden”. En Neue Juristische Wochenschrift (NJW), pp. 2220-2228.

Michalke, Regina (1994): "Die Strafbarkeit von Amtsträgern wegen Gewässerverunreinigung ( $\$ 324$ StGB) und umweltgefährdender Abfallbeseitigung ( 3326 StGB) in neuem Licht”. En Neue Juristische Wochenschrift (NJW), pp. 1693-1698.

Mittelsdorf, Kathleen (2007): Unternehmensstrafrecht im Kontext. Heidelberg C. F. Müller.

Otto, Harro (1991): “Grundsätzliche Problemstellungen des Umweltstrafrechts”. En Juristische Ausbildung (Jura), pp. 308-316.

Ransiek, Andreas (2005a): “Vor § 324 StGB”. En Nomos Kommentar zum Strafgesetzbuch, Tomo 2. Baden-Baden: Nomos, segunda edición.

(2005b): “§ 324 StGB”. En Nomos Kommentar zum Strafgesetzbuch, Tomo 2. Baden-Baden: Nomos, segunda edición.

Ripollés, José Luis Díez (2001): "Symbolisches Strafrecht und die Wirkungen der Strafe”. En Zeitschrift für die gesamte Strafrechtswissenschaft (ZStW), pp. 516-538.

Rogall, Klaus (1991): Die Strafbarkeit von Amtsträgern im Umweltbereich. Berlín: Erich Schmidt.

Rudolphi, Hans-Joachim (2000): “§ 13 StGB”. En Systematischer Kommentar zum Strafgesetzbuch, Tomo 1. Munich: Luchterhand, séptima edición. (1994): “Anmerkung zu Urteil des BGH vom 03/11/1993-2 StR 321/93”. En Neue Zeitschrift für Strafrecht (NStZ), pp. 433-436.

- (1982): "Probleme der strafrechtlichen Verantwortlichkeit von Amtsträgern für Gewässerverunreinigungen”. En Ernst-Walter Hanack, Peter Rieß, Günter Wendisch (eds.), Festschrift für Hanns Dünnebier, pp. 561-583. Berlín, Nueva York: De Gruyter.

Schall, Hero (1993): "Zur Strafbarkeit von Amtsträgern in UmweltverwaltungsbehördenBGHSt 38, 325”. En Juristische Schulung (JuS), pp. 719-724. (1990): "Umweltschutz durch Strafrecht: Anspruch und Wirklichkeit”. ·En Neue Juristische Wochenschrift (NJW), pp. 1263-1273.

Schall, Hero y Marcus Schreibauer (1996): "Gegenwärtige und zukünftige Sanktionen bei Umweltdelikten”. En Natur und Recht (NuR), pp. 440-450. 
Schirrmacher, Gesa (1995): “Anmerkung zu Urteil des BGH vom 03/11/1993-2 StR 321/ 93”. En Juristische Rundschau (JR), pp. 386-391.

Schmitz, Roland (2006): “Vor §§ 324 StGB”. En Münchener Kommentar zum Strafgesetzbuch, Tomo 4. Munich: C. H. Beck.

Schünemann, Bernd (2007a): “Vor § 25 StGB”. En Leipziger Kommentar zum Strafgesetzbuch, Tomo 1. Berlín: De Gruyter Recht, duodécima edición. (2007b): “§ 25 StGB”. En Leipziger Kommentar zum Strafgesetzbuch, Tomo 1. Berlín: De Gruyter Recht, duodécima edición.

(2003): "Das Strafrecht im Zeichen der Globalisierung”. En Goltdammer's Archiv für Strafrecht (GA), pp. 299-313.

- (1996): “Zur Dogmatik und Kriminalpolitik des Umweltstrafrechts”. En Kurt Schmoller (ed.), Festschrift für Otto Triffterer, pp. 437-456. Viena: Springer.

(1995): "Kritische Anmerkungen zur geistigen Situation der deutschen Strafrechtswissenschaft”. En Goltdammer's Archiv für Strafrecht (GA), pp. 201229.

(1994): "Die Strafbarkeit der juristischen Personen aus deutscher und europäischer Sicht”. En Bernd Schünemann y Carlos Suárez Gonzáles (eds.), Bausteine des europäischen Wirtschaftsstrafrechts - Madrid Symposium für Klaus Tiedemann, pp. 265-295. Colonia: Heymanns.

(1986): "Die Strafbarkeit von Amtsträgern im Gewässerstrafrecht”. En Zeitschrift für Wirtschafts- und Steuerstrafrecht (wistra), pp. 235-246.

- (1971): Grund und Grenzen der unechten Unterlassungsdelikte. Göttingen: Schwartz.

Schwind, Hans-Dieter (2008): Kriminologie. Heidelberg: Hüthig Jehle Rehm, decimoctava edición.

Simon, Jonathan (2007): Governing through Crime. Oxford: Oxford University Press.

Sparwasser, Reinhard; Rüdiger Engel y Andreas Voßkuhle (2003): Umweltrecht. Heidelberg: C. F. Müller, quinta edición.

Steindorf, Joachim (1997a): "Vor § 324 StGB”. En Leipziger Kommentar zum Strafgesetzbuch, Tomo 8. Berlín: De Gruyter Recht, decimoprimera edición. (1997b): “§ 324 StGB”. En Leipziger Kommentar zum Strafgesetzbuch, Tomo 8. Berlín: De Gruyter Recht, decimoprimera edición.

Tiedemann, Klaus y Urs Kindhäuser (1988): "Umweltstrafrecht - Bewährung oder Reform?”. En Neue Zeitschrift für Strafrecht (NStZ), pp. 337-346.

Winkelbauer, Wolfgang (1998): "Umweltstrafrecht und Unternehmen”. En Albin Eser, Ulrike Schittenhelm y Heribert Schumann (eds.), Festschrift für Theodor Lenckner, pp. 645-659. Munich: C. H. Beck.

Wohlers, Wolfgang (1996): "Der Erlaß rechtsfehlerhafter Genehmigungsbescheide als Grundlage mittelbarer Täterschaft”. En Zeitschrift für die gesamte Strafrechtswissenschaft (ZStW), pp. 61-85. 